ROBERTA MARQUES BENAZZI VILLAVERDE

\title{
PERSONALIDADE JURÍDICA DO ANENCÉFALO
}

\author{
Tese de Doutorado
}

Orientadora: Professora Titular Teresa Ancona Lopez

Faculdade de Direito da Universidade de São Paulo São Paulo 
ROBERTA MARQUES BENAZZI VILLAVERDE

\section{PERSONALIDADE JURÍDICA DO ANENCÉFALO}

Tese apresentada à Faculdade de Direito da Universidade de São Paulo para obtenção do título de Doutora em Direito.

Área de Concentração: Direito Civil

Orientadora: Professora Titular Teresa Ancona Lopez

Faculdade de Direito da Universidade de São Paulo

São Paulo

2011 
Nome: VILLAVERDE, Roberta Marques Benazzi

Título: Personalidade Jurídica do Anencéfalo

Tese apresentada à Faculdade de Direito da Universidade de São Paulo para obtenção do título de Doutora.

Aprovado em:

Banca Examinadora:

Prof. Dr. Instituição:

Julgamento: Assinatura:

Prof. Dr. Instituição:

Julgamento: Assinatura:

Prof. Dr. Instituição:

Julgamento: Assinatura:

Prof. Dr. Instituição:

Julgamento: Assinatura:

Prof. Dr. Instituição:

Julgamento: Assinatura: 
Ao meu marido, HeNRIQUe BERLOFA VILLAVERDE, grande amor da minha vida, pelo incansável apoio, pelo exemplo de existência e de dedicação, pelas incontáveis horas que deixei de estar ao seu lado, por compartilhar comigo este grandioso sonho e todos os ideais de vida.

A minha mãe, GLORIa SANTIAGO MARQUES BENAZZI, pela inspiração e por sua história de superação, pela batalha compartilhada a cada dia desta jornada, pelo amor incondicional, pela devoção integral, enfim, por tudo.

A meu pai, DINo BENAZZI, que me deu o dom da vida, a oportunidade de realizar o utópico e o real, pelas palavras de incentivo e de apoio em todos os momentos desta longa caminhada.

A minha irmã, RAQUEL MARQUES BENAZZI, amiga de todas as horas, companheira emérita de todas as lágrimas e sorrisos despendidos em cada página deste trabalho.

A minha tia, MARIA FATIMA SANTIAGo MARQUES DUTRA, pelo arquétipo exemplar de pessoa e de profissional, pelos momentos mais memoráveis, pela presença constante e incansável em todos os momentos de minha vida.

Aos meus avós, ALDO, REGINA, WALTER e BERENICE (in memoriam) pelo amor insuperável, pelas lições de vida, pela certeza de meu crescimento e sucesso. 


\section{AGRADECIMENTOS}

À Profa. Dra. Teresa Ancona Lopez, que me deu a oportunidade do estudo, das preciosas horas ao seu lado, pela incansável dedicação, pelo carinho, pelo amor maternal que sempre dedicou a cada um de seus alunos. Mulher de fibra, de grande profissionalismo e lapidar conhecimento, sempre me serviu de exemplo a ser seguido. Além de agradecê-la por tudo, não posso deixar de registrar minha honra e meu orgulho em tê-la como minha orientadora, minha eterna professora.

Ao meu marido, Henrique Berlofa VillaVerde, pelas horas de discussão a respeito de tão palpitantes temas, pela incansável batalha em busca de material doutrinário e legislativo, pelo investimento emocional e pessoal constante em mim e no produto deste trabalho.

À Profa. Dra. Patrícia Faga Iglecias Lemos por todo incentivo, pelo auxílio constante, pela paciência de todos os momentos, pela disponibilidade, por sempre me acrescentar.

Ao Dr. GILBERTo Bergstein por ter me auxiliado em diversos momentos, pela lembrança constante do tema da presente tese, pelo farto material disponibilizado, por ter aberto as portas de sua casa e ter abrigado os sonhos do presente trabalho.

À minha mãe, Gloria Santiago Marques Benazzi, e à minha tia, Maria Fatima SANTiago Marques Dutra pela incansável busca de artigos e jornais antigos relacionados ao estudo em questão, por se preocuparem a cada segundo com a pesquisa a ser realizada.

À minha irmã, RAQuel MARQues BenAZZI, pela troca de experiências e pela pesquisa de campo na temática traçada pela presente tese.

À FAPESP, pela bolsa de doutorado concedida no período de 01 de setembro de 2008 a 27 de janeiro de 2011 e por todo apoio e incentivo à pesquisa. 


\section{RESUMO}

A tese de doutorado que ora se apresenta trata do diagnóstico da anencefalia e seus desdobramentos para o Direito, em especial no que tange à existência ou não de personalidade jurídica em seus portadores. Analisam-se, então, os princípios informadores que se relacionam com a matéria em questão, demonstrando a existência de diferentes planos de apreciação. O trabalho explora, ainda, os direitos da personalidade, discutindo as diferentes teorias que se pronunciam acerca do momento em que a personalidade jurídica se inicia, destacando quais as consequências que derivam da adoção de uma ou outra teoria. A pesquisa traça conceitos e distinções, como a diferenciação entre personalidade e capacidade. Trata-se, então, dos momentos que limitam a existência humana, discorrendo acerca dos marcos em que se inicia e termina a vida humana. Ao cuidar do fim da existência humana, arrolam-se os diferentes conceitos de morte, com as consequências de cada um na seara jurídica. Neste ponto, destaca-se a morte encefálica, com enfoque na Lei de Transplantes de Órgãos e Tecidos. A análise deste panorama deságua no estudo da anencefalia, com posições médicas sobre esta doença, levantando-se os demais casos de anomalias encefálicas que podem se apresentar em um ser humano, bem como suas implicações na vida biológica e relacional daquele ser. Analisa-se, então, a aplicação dos critérios de morte encefálica no que tange à anencefalia, traçando as perspectivas de vida que um ser nestas condições apresenta. Discorre-se acerca da existência de vida e sua manutenção nos casos em esta anomalia é detectada. Uma abordagem sobre a interrupção da gestação nos casos de diagnóstico pré-natal desta doença é realizada, com enfoque na atual tipificação do crime de aborto, nas suas excludentes de ilicitude, nos conceitos de aborto eugênico e aborto anencefálico e as decorrências jurídicas de cada um deles. Os resultados são comparados com as posições dos Tribunais brasileiros e estrangeiros sobre o aborto anencefálico, colocando o debate que existe sobre as ações de Wrongful Life e Wrongful Birth. Cuida-se, por fim, da situação do anencéfalo nascido, que venceu a barreira da gestação, colocando o debate médico que existe sobre a viabilidade de existência extrauterina, com a repercussão jurídica na atribuição ou não de personalidade a este ser. Conclui-se que portadores de anencefalia são dotados de personalidade jurídica, explicitando a não aplicação dos conceitos de morte encefálica em seu diagnóstico. 


\begin{abstract}
The scope of this present Doctoral Dissertation comprises the diagnosis of anencephaly and its involvement with Law, especially in what concerns the problem of bearers thereof having or not a juridical personality. Informing principles relevant to the matter at issue are then analysed, and two different plans come into evidence for appreciation. Personality rights and different theories on the moment when the legal personality begins are also examined and discussed so as to highlight the consequences deriving from each theory. Concepts and distinctions are elicited by this research, such as differentiation between personality and capacity. The moments limiting human existence are then studied by considering the initial and final landmarks of human life. When dealing with the end of human life, different concepts of death are evoked, as well as the consequences of each one in the juridical field. Encephalic death is then highlighted with a focus on the Organ and Tissue Transplant Law. Analysis of this panorama leads to the study of anencephaly and medical opinions on this disease, while examining all the other cases of encephalic anomalies a human being is prone to, as well as their implications in the biological and relational life of such beings. The application of encephalic death criteria to cases of anencephaly is then analysed on the basis of life perspectives expected for a human being in such conditions. The conditions of existence and life maintenance once such anomaly is detected are discussed. A possible termination of pregnancy in cases of early diagnosis of this disease makes the object of an approach in the light of not only the current characterization of abortion as a crime, but also of the elements excluding its illicit character, concepts concerning eugenic abortion and anencephalic abortion, as well as of the legal consequences of each one of these cases of exclusion. The results are compared to Brazilian and foreign courts' positions with respect to anencephalic abortion, placing the existing debate on actions of Wrongful Life and Wrongful Birth. Finally, attention is given to the situation of the anencephalic infant who has overcome the gestation barrier, raising medical argumentation about the viability of extrauterine existence without juridical repercussion on the dilemma of attributing or not juridical personality to such a being. It is concluded that bearers of anencephaly are entitled to legal personality, non-application of encephalic death concepts to such diagnosis being therefore explicit.
\end{abstract}




\section{RIASSUNTO}

La presente tesi di dottorato tratta della diagnosi di anencefalia e le rispettive conseguenze giuridiche, soprattutto per quanto riguarda l'esistenza o la mancanza di personalità giuridica di coloro che sono portatori di tale malattia. Si analizzano, allora, i principi che hanno rapporti con l'oggetto in questione, dimostrando l'esistenza di diversi livelli di valutazione. Questo lavoro esplora anche i diritti della personalità, discutendo le diverse teorie rispetto al momento in cui si inizia la personalità giuridica, sottolineando quali sono le conseguenze che derivano se una o altra teoria viene considerata. La ricerca espone concetti e distinzioni, come il differenziamento tra personalità e capacità. Si tratta, allora, dei momenti che limitano l'esistenza umana, discorrendo sui segni che indicano l'inizio e la fine della vita umana. Quando si tratta della fine dell'esistenza umana, diversi concetti di morte vengono elencati, oltre le conseguenze di ognuno nell'ambito giuridico. A questo punto viene trattata la questione della morte encefalica, con un approccio especiale alla Legge di Trapianti d'Organi e Tessuti. L'analisi di questo quadro sbocca nello studio della anencefalia, con opinioni mediche rispetto a questa malattia, e nelle altre possibilità di anomalie encefaliche che possono succedere ad un essere umano, oltre le loro implicazioni nella vita biologica e nei rapporti di tale essere. Per quanto riguarda l'anencefalia l'uso dei criteri che stabiliscono la morte encefalica viene analizzato, delineando le prospettive di vita che un essere in tali condizioni può avere. C'è la discussione intorno all'esistenza di vita e il suo mantenimento quando la malattia è scoperta. Un approccio sull'interruzione di gravidanza nei casi di diagnosi prenatale di questa malattia viene realizzato, facendo speciale attenzione alla presente tipificazione del crime di aborto e le cause di esclusioni del reato, nei concetti di aborto eugenetico e aborto anencefalico e le implicazioni giuridiche di ognuno. I risultati vengono paragonati con le opinioni dei tribunali brasiliani e stranieri rispetto l'aborto anencefalico, segnalando il dibattito che c'è tra le azioni di Wrongful Life e Wrongful Birth. Si tratta, alla fine, della situazione dell'anencefalo nato che ha vinto la barriera della gestazione, presentando il dibattito medico rispetto la viabilità della vita extrauterina, con la ripercussione giuridica nella attribuzione della personalità a questo essere o no. Si conclude che i portatori di anencefalia sono dotati di personalità giuridica, esplicitando che non si deve utilizzare i concetti di morte encefalica nella diagnosi. 


\section{SUMÁRIO}

INTRODUÇÃO

1 FUNDAMENTOS E VALORES QUE SUSTENTAM

A PROTEÇÃO DA PESSOA HUMANA ............................. Erro! Indicador não definido.

1.1 Planos de análise. Erro! Indicador não definido.

1.2 Princípios informadores Erro! Indicador não definido.

1.2.1 Dignidade da pessoa humana . Erro! Indicador não definido.

1.2.2 Proteção à vida. Erro! Indicador não definido.

1.2.3 Princípios bioéticos Erro! Indicador não definido. 1.2.4 Princípio da proporcionalidade Erro! Indicador não definido.

2 DIREITOS DA PERSONALIDADE

Erro! Indicador não definido.

2.2 Conceito Erro! Indicador não definido.

2.3 Classificações Erro! Indicador não definido.

2.4 Natureza jurídica Erro! Indicador não definido.

2.5 Direitos da personalidade da mãe e do nascituro Erro! Indicador não definido. 2.5.1 Direitos da personalidade da gestante Erro! Indicador não definido. 2.5.2 Direitos da personalidade do nascituro Erro! Indicador não definido.

3 INÍCIO DA VIDA

Erro! Indicador não definido.

3.1 Teoria concepcionista Erro! Indicador não definido.

3.2 Teoria nidista (nidação) Erro! Indicador não definido.

3.3 Teoria embriológica Erro! Indicador não definido.

3.4 Teoria neurológica ou do sistema nervoso central .. Erro! Indicador não definido.

3.5 Teoria tecnológica ou ecológica ..... Erro! Indicador não definido.

3.6 Teoria senciente Erro! Indicador não definido.

3.7 Teoria fisiológica Erro! Indicador não definido.

3.8 Teoria metabólica Erro! Indicador não definido.

3.9 Teoria do reconhecimento Erro! Indicador não definido.

3.10 Código de Ética Médica. Erro! Indicador não definido.

3.11 Análise crítica Erro! Indicador não definido.

4 INÍCIO DA PERSONALIDADE CIVIL

Erro! Indicador não definido.

4.1 Teorias Erro! Indicador não definido.

4.1.1 Teoria natalista Erro! Indicador não definido.

4.1.2 Concepcionista. Erro! Indicador não definido.

4.1.3 Personalidade condicional Erro! Indicador não definido.

4.1.4 Viabilidade da vida e forma humana Erro! Indicador não definido. 4.2 Conceitos de personalidade e capacidade Erro! Indicador não definido.

5 FIM DA EXISTÊNCIA HUMANA

Erro! Indicador não definido.

5.1 Conceito de morte encefálica. Erro! Indicador não definido.

5.2 Lei de Transplantes.... Erro! Indicador não definido.

5.3 Fim da personalidade. Erro! Indicador não definido.

5.4 Efeitos civis da decretação de morte Erro! Indicador não definido. 
6 ANENCÉFALO

Erro! Indicador não definido.

6.1 Conceito Erro! Indicador não definido.

6.2 Posições médicas sobre anencefalia Erro! Indicador não definido.

6.3 Posições jurídicas sobre anencefalia Erro! Indicador não definido.

6.3.1 Existência de vida Erro! Indicador não definido.

6.3.2 Interrupção da gestação Erro! Indicador não definido.

6.4 Posição dos tribunais sobre o aborto anencefálico .. Erro! Indicador não definido. 6.5 Wrongful life e wrongful birth Erro! Indicador não definido.

7 ANENCÉFALO NASCIDO E SUA PERSONALIDADE Erro! Indicador não definido.

7.1 Viabilidade de existência extrauterina Erro! Indicador não definido.

7.2 Existência ou não de personalidade jurídica Erro! Indicador não definido.

7.3 Efeitos jurídicos da atribuição de personalidade jurídica ao anencéfalo Erro! Indicador não definido.

CONCLUSÃO 304

BIBLIOGRAFIA 309

ANEXOS 340 


\section{INTRODUÇÃO}

A temática da anencefalia desperta não apenas diferentes posições, mas também sensações que passam pela efemeridade da vida e pela certeza da morte.

$\mathrm{O}$ assunto normalmente é referido na doutrina e na mídia abordando a possibilidade do aborto nestas condições, de modo que todo o debate passa ao largo da situação do anencéfalo nascido, com todas as angústias e dúvidas que cercam este momento.

A precária atividade encefálica do neonato com esta anomalia é diagnosticada por alguns médicos e doutrinadores como morte encefálica, encetando sobre o recémnascido uma sentença de morte que lhe retira a parca proteção que poderia obter do ordenamento jurídico.

A personalidade jurídica, então, acaba não sendo reconhecida ao ser humano com estas condições, despojando-o das normas essenciais que garantem uma existência, ainda que efêmera, com a qualidade e a dignidade que a condição humana requer.

A construção dos argumentos que demonstram outra realidade acaba sendo relegada a um segundo plano, vez que a pavimentação desta estrada parece ser contrária à interrupção de uma gestação anencefálica.

Contudo, a situação do aborto não se confunde com a condição do nascido anencéfalo, havendo outras justificativas hábeis a permitir a interrupção de uma gravidez nestas condições sem passar pelo atestado de óbito do feto.

A presença de vida é tão pulsante como seu próprio coração e sua existência é tão frágil quanto o ar que sopra de seus pulmões. Assim, a presente tese busca analisar os conceitos jurídicos de vida e morte, estabelecendo quais os limites que encerram a experiência humana.

Neste sentido, a Lei de Transplantes de Órgãos e Tecidos traça parâmetros que, juntamente com enunciados do Conselho Federal de Medicina, indica qual a solução deve ser dada a temática em apreço.

Esse estudo é isento de juízos religiosos, pautando suas conclusões em normas jurídicas e médicas, analisando cuidadosamente a biologia que conforma o indivíduo, em especial sua condição encefálica. 
A personalidade jurídica é instituto criado com o intuito de proteger um sujeito de direitos e de deveres das arbitrariedades estatais, bem como do campo da individualidade de outros semelhantes. Ser pessoa é condição que insere um indivíduo como integrante do corpo social, sujeitando-o ao conjunto de normas e de garantias que encerra a vida em comunidade.

Os direitos da personalidade, como direitos humanos que são, ressaltam a fragilidade de um indivíduo frente ao império estatal e a outros indivíduos mais fortes, despindo o ser humano de seu estado de natureza para inseri-lo no convívio com outras instituições.

A existência, então, é condição primordial de toda a humanidade, sendo certo que o ser humano é um ser gregário por natureza, necessitando de outros da mesma espécie para sobreviver ao meio que o cerca.

A diversidade da constituição humana é inerente a esta pluralidade de vivências, de modo que o diferente é condição necessária de preservação da espécie. Esta variedade deve ser resguardada, garantindo aos desiguais condições que the assegurem parâmetros semelhantes de respeito e de dignidade.

A presença de anomalias ou deficiências constitui razão para o surgimento de normas protetivas que garantam paridade de tratamento a pessoas despojadas biologicamente de condições fundamentais na sobrevivência de um ser humano.

Dessa feita, essas malformações físicas ou genéticas devem ser preservadas como condição própria de nossa espécie, rejeitando-se qualquer argumento de ordem eugênica.

A eugenia, por seu turno, foi política central do regime nazista, de modo que o mundo experimentou as maiores atrocidades já vistas sob o pálio deste argumento, anulando qualquer raça diferente da ariana.

Sendo assim, o anencéfalo, como portador de uma malformação, deve ser preservado em sua vida e dignidade, garantindo que a volatilidade de sua existência seja dotada de um significado jurídico e social, atestando que seu nascimento não foi desconsiderado por um ordenamento que se diz democrático.

Os direitos da personalidade, então, possuem como titular qualquer pessoa, seja ela portadora de uma limitação física, mental ou de uma anomalia genética. A condição de pessoa não pode ser deferida a alguns poucos, excluindo por completo vivências ímpares, que por sua diversidade não experimentam as mesmas representações e sentimentos que os demais seres humanos. 
A presente tese, por conseguinte, procura despir os argumentos entoados pela doutrina e jurisprudência de seu viés religioso, eugênico ou utilitarista, transparecendo a real situação que os portadores de anencefalia estão sujeitos quando transpassam todas as dificuldades de uma turbulenta gestação, desnudos de uma proteção que a lei lhes garante. 


\section{CONCLUSÃO}

A vida, milagre pulsante que descortina uma existência repleta de possibilidades, seria um fenômeno puramente biológico ou poderia ser ela delimitada por normas jurídicas alheias às complexidades que habitam o funcionamento do corpo humano? Poderia um dispositivo excluir determinados seres humanos da categoria de seres vivos, regulando de forma contudente o derradeiro momento de uma jornada?

O universo das normas jurídicas é essencial para regular uma vida em sociedade, mas a falta de harmonia entre seus dispositivos leva a antinomias insanáveis, cuja resposta será dada por instrumentos institucionalizados como capazes de solucionar a problemática imposta.

A situação do anencéfalo não se encaixa de forma hermética na configuração da morte encefálica, sendo certo que a existência de um tronco encefálico, com reflexos a ele inerentes, garante a este ser a constatação da existência de uma vida biológica e encefálica, ainda que precária.

A delicadeza dos neonatos traça diversas complicações médicas logo em seus primeiros dias de vida, de modo que a morte de recém-nascidos prematuros é uma possibilidade cuja constatação não se distingue da efêmera existência do anencéfalo.

Ainda que a certeza da morte do ser anencefálico seja um dado biológico, o breve período de vida que foi por ele experimentado não pode ser ignorado pelo direito e pela sociedade, sendo inseguro elastecer conceitos jurídicos e critérios médicos para conformar a situação de um ser em uma categoria que não foi para ele criada, desconsiderando suas peculiaridades.

O universo jurídico tende a acreditar ser o centro de toda ciência, aglutinando em seu seio uma vasta gama de matérias cujos meandros não são afetos à seara do direito. A tentação é ainda maior quando a regulamentação encerra divergências, como se um dispositivo colocasse ponto final aos anseios sociais.

Não há como olvidar, conforme já mencionado, as barbáries cometidas no período nazista sob o pálio do direito, conformando toda sorte de abusos e violências a 
normas jurídicas, as quais legitimavam a ordem de coisas impostas pelo líder de uma nação. O positivado nem sempre corresponde ao justo ou deriva do consenso social, sendo certo que o jurídico não é resposta para todas as agonias humanas.

Dessa feita, a anencefalia, como doença genética que é, aspira por uma categorização dentro da legislação vigente, sem, contudo, aceitar uma distorção de conceitos já existentes para responder a sua situação.

A morte encefálica é, como afirmado por Peter Singer, uma ficção que soluciona a problemática do transplante de órgãos e tecidos, impondo ao ser humano desprovido de chances de sobrevivência uma utilidade que transcende sua própria vida. Dessa feita, o esgotamento da atividade encefálica de um indivíduo o transforma em fornecedor do suporte orgânico que outros seres da mesma espécie necessitam para prolongar seu tempo de vida.

A inviabilidade da vida de alguns traça uma possibilidade, uma esperança para outros que vislumbram a proximidade do final de sua existência. Essa visão utilitarista do ser humano deve prosperar ante a fiel constatação dos critérios definidores de morte encefálica, através de rigoroso procedimento que não deve ceder espaço a outras considerações.

A ausência de consentimento pessoal ou familiar para levar a efeito o transplante de órgãos impede, a nosso ver, a constatação do óbito daquele indivíduo. A morte encefálica tem sua razão de existir na Lei de Transplantes de Órgãos e Tecidos, de modo que a discordância com referida doação retira a aplicação do dispositivo em questão, passando a situação daquele indivíduo a ser tutelada pelas demais normas jurídicas.

Dessa feita, o pressuposto da ingerência da Lei de Transplantes na constatação da morte de um ser humano é o consentimento com a doação de seus órgãos e a possibilidade de seu diagnóstico pelos critérios sedimentados em conhecimentos médicos.

Não fosse assim, uma pessoa com morte encefálica, cuja doação de órgãos não foi autorizada, mantida sob o suporte mecânico e instrumental de aparelhamentos médicos por longos anos, seria um sujeito anômalo para o Direito, configurando verdadeiro "morto vivo" no seio social. Teríamos a aberração da abertura de inventários e a transmissão de direitos hereditários de pessoas instaladas em um leito de hospital.

A fugacidade de uma vida não é fundamento suficiente para atestar prematuramente o óbito de um ser humano. Ao anencéfalo, considerado o fato de estar vivo, são reconhecidos e tutelados todos os direitos assegurados aos demais neonatos não portadores desta anomalia. 
Assim, a brevidade da vida, por si só, não deve servir de argumento para autorizar a constatação da morte de uma pessoa, sendo corolário da segurança jurídica a estrita observância aos critérios estabelecidos pelas normas jurídicas e médicas.

A morte encefálica abrevia a vida de um ser humano para um momento anterior a sua morte biológica, garantindo, assim, a qualidade e preservação dos órgãos e tecidos daquele indivíduo, afiançando o sucesso da cirurgia que irá transferir o instrumentário vital de um ser vivo para outro.

A atividade cerebral do anencéfalo, a despeito de não ser compatível com uma consciência e uma vinculação com o meio que o cerca, é responsável pela manutenção de reflexos sensoriais como respiração e batimentos cardíacos, sem a necessidade de suporte mecânico para esta manutenção vital.

A troca de gases com o meio ambiente é fato certo, de modo que o anencéfalo respira ao nascer, fator este que grita o seu nascimento da mesma forma como grita ao mundo a existência de sua vida. Aliás, caso fosse realizado o teste da apneia, exame necessário para constatar a morte encefálica de uma pessoa, o ser anencefálico responderia ao mesmo com a presença de uma atividade respiratória espontânea, destruindo os argumentos que sustentam a ausência de vida destes neonatos.

O reconhecimento de uma personalidade jurídica ao anencéfalo confere a ele o status de pessoa, podendo figurar como sujeito de direitos e deveres na órbita jurídica. Ainda que se defira aos seres humanos falecidos alguma proteção a certos direitos da personalidade, é certo que este reconhecimento não é suficiente para tutelar toda a gama de situações que a fragilidade destes seres exige.

A redoma protetora dos direitos da personalidade garante o respeito à condição de pessoa, resguardando direitos inatos aos seres humanos e conferindo ao indivíduo voz ativa frente às estruturas de poder.

A personalidade jurídica do anencéfalo tutela os direitos pessoais e patrimoniais que lhe foram resguardados desde a concepção, considerando seu nascimento como evento capaz de materializar e concretizar a aquisição de uma vida que era esperada. O nascimento com vida do anencéfalo consolida o que até então era, para alguns doutrinadores, uma mera expectativa de direitos.

Dessa feita, o nascimento com vida do anencéfalo, atestado pela entrada espontânea de ar em seus pulmões, defere a ele a qualidade de herdeiro, a aquisição de direitos patrimoniais e não patrimoniais, bem como solidifica sua existência pelo registro de nascimento e, quando do seu óbito, da certidão de óbito. 
Esta constatação traz consigo um nome e um sobrenome ao portador de tal anomalia, confortando a plenitude e a fugacidade de sua vida na tutela jurídica que equipara todos os seres humanos, confirmando que são todos iguais perante a lei, independemente de anomalias ou malformações.

A pavimentação desta arquitetura não é desconectada da legislação, vez que a declaração da personalidade jurídica nestes casos é resultado da análise estrita das normas vigentes, desconstruindo os argumentos que elastecem conceitos e critérios normativos, procurando encaixar realidades distintas em valas comuns.

O reconhecimento da personalidade do anencéfalo é decorrência de sua dignidade, da certeza de que a existência de um ser humano, por mais singela e volátil que seja, merece respeito e proteção.

Sendo assim, o anencéfalo possui a qualidade de pessoa, motivo este suficiente para lhe deferir a qualidade de herdeiro, de titular de direitos e deveres, direitos estes de conteúdo patrimonial ou personalíssimo.

O gozo e a fruição de todos os direitos assentados em uma legislação interna e também na órbita internacional é decorrência direta do entendimento segundo o qual o anencéfalo é pessoa, sendo sua vida fato inegável.

Não se pode olvidar que o nascimento de uma criança é sempre acompanhado pela expectativa de uma nova vida, de uma existência repleta de possibilidades, configurando um rascunho em branco, o qual deverá ser lentamente preenchido pelas ranhuras do desenvolvimento humano.

A anencefalia, como malformação incompatível com uma longa existência extrauterina, retira o colorido das linhas em branco, tornando o rascunho passível de descarte sem qualquer escrito.

Esta efêmera jornada, contudo, não difere seu peregrino daqueles que trilham longos caminhos e alcançam o cume das mais altas montanhas. A qualidade de uma vida só deve ser aferida por aquele que a vive, não sendo dever da sociedade tarjar determinadas deficiências como desqualificadoras dos movimentos vitais que conferem ação ao espetáculo da existência humana.

O anencéfalo não é menos humano ou menos pessoa em razão da malformação que porta. O choro com o qual ele cumprimenta a vida é o verdadeiro atestado de seu nascimento, com todas as qualidades atribuídas a qualquer ser humano.

Ele é merecedor do amparo que o ordenamento jurídico confere aos sujeitos de direitos, atribuindo-lhe o título de pessoa. Esta singela denominação iguala a todos perante 
a onipotência do legislador, dedicando tratamento equânime a condições análogas, sem jamais retirar o piso garantidor da existência social.

O indivíduo, com todas as características que o diferencia de seus pares, é o elo que representa a aderência da sociedade ao Direito, sendo o destinatário da norma que confere a máxima eficácia ao texto legal.

Destarte, corroborar com a discriminação legislativa é desconsiderar que a diferença entre os seres humanos é o que torna cada existência única. A desigualdade deve existir apenas e tão somente quando seu intuito for a equiparação de fato pela desigualdade de direito.

Logo, ao anencéfalo devem ser atribuídas maiores garantias que aos demais, vez que sua deficiência exige um amparo legislativo compatível com a desigualdade biológica que lhe foi imposta pela gestação.

A ausência de consciência ou capacidade mental não diminui sua condição humana, tampouco o equipara a outros reinos animais. Seu nascimento, então, é a verdadeira comprovação de que somos seres dependentes uns dos outros e de que a diversidade é o elemento que garante a sobrevivência de nossa espécie.

Conclui-se, então, a presente tese com as palavras de Jean Paul Sartre:

“(...) o outro é indispensável a minha existência tanto como o conhecimento que tenho de mim mesmo"

\footnotetext{
${ }^{1}$ SARTRE, Jean Paul. El existencialismo es um humanismo. 2. ed. Buenos Aires: Losada, 2002. p. 33.
} 


\section{BIBLIOGRAFIA}

ABDALLA SEMIÃO, Sérgio. Os direitos do nascituro. Aspectos cíveis e criminais e do biodireito. Belo Horizonte: Del Rey, 1998.

AGUIAR, Joaquim. Programa de direito civil: introdução e parte geral. 2. ed. São Paulo: Cargine, 1974.

AGUIAR, Roberto A. R. de. Alteridade e rede no direito. Revista Veredas do Direito. Belo Horizonte: Escola Superior Dom Helder Câmara, n. 6, v. 3, p. 11-43, jul.-dez. 2006.

ALATIS, A. J. Organ harvesting from anencephalic infants: health management over a sinkhole. Health Matrix, n. 4, v. 6, p. 3-11, California, Owings Mills, Md.: National Law Publishing affiliated with National Health Publishing,1988-1989.

ALEXY, Robert. Rechtssystem und praktische Vernunft. In: ALEXY, Robert. Recht, Vernunft, Diskurs:Studien zur Rechtsphilosophie. Frankfurt am Main: Suhrkamp, 1995. . Rechtsregeln und Rechtsprinzipien. In: ALEXY, Robert, Archives Rechts und

Sozialphilosophie, Beiheft 25, 1985, wieder abgedruckt in: R. Alexy/H.-J. Koch/ L. Kuhlen/H. Rüßmann, Elemente einer juristischen Begründungslehre, Baden-Baden, 2003. . Theorie der Grundrechte. 2. ed. Frankfurt am Main: Suhrkamp, 1994.

Zum Begriff des Rechtsprinzips. In: ALEXY, Robert. Argumentation und

Hermeneutik in der Jurisprudenz, Rechtstheorie, Beiheft 1, Berlin: Dunckler und Humblot, 1979.

ALMEIDA, Silmara J. A. Chinellato e. Direitos de personalidade do nascituro. Revista do Advogado, n. 38, p. 22-23, São Paulo, Associação dos Advogados de São Paulo, dez. 1992.

. Tutela civil do nascituro. São Paulo: Saraiva, 2000.

ALMEIDA JÚNIOR, Josualdo Eduardo de. Alimentos gravídicos. Revista IOB de direito de Família, n. 51, p. 30-44, dez.-jan. 2009, v. 9.

ALVARENGA, Dílio Procópio Drummond de. Anencefalia e aborto. Jus Navigandi, Teresina, ano 9, n. 324, 27 maio 2004. Disponível em: http://jus.uol.com.br/revista/texto/5167. Acesso em: 08 ago. 2011.

ALVES, João Luiz. Código Civil anotado. Rio de Janeiro: F. Briguiet, 1917. 
ALVES, José Carlos Moreira. A forma humana no direito romano. Tese para provimento de Cátedra. Rio de Janeiro, 1960. v. 1, 77 p. . A parte geral do Projeto de Código Civil Brasileiro: subsídios históricos para o novo Código Civil Brasileiro. 2. ed. São Paulo: Saraiva, 2003. Direito romano. 13. ed. Rio de Janeiro: Forense, 2001. v. 1.

ALVES, Leonardo Barreto Moreira. O direito de nascer do ventre de mãe morta e demais questões afins: o caso Marion Ploch. Jus Navigandi, Teresina, ano 6, n. 59, out. 2002. Disponível em: http://jus2.uol.com.br/doutrina/texto.asp?id=3276. Acesso em: 29 jul. 2010.

ALVES, Oziel. Células embrionárias podem curar doenças. Revista Enfoque, edição 82, maio 2008.2 Disponível em: http://www.revistaenfoque.com.br/index.php?edicao=82\&materia=1050. Acesso em: 27 set. 2008.

AMARAL, Francisco. Direito civil: introdução. 3. ed. rev., atual. e aum. Rio de Janeiro: Renovar, 2000.

. Direito civil: introdução. 4. ed. Rio de Janeiro: Renovar, 2000.

. Direito civil: introdução. 5. ed. rev., atual. e aum. Rio de Janeiro: Renovar, 2003.

AMATRIAIN, Roberto Cataldi. Alcances del principio de autonomia en medicina. In: ENGELHARDT, Dietrich Von; MAINETTI, José Alberto; AMATRIAIN, Roberto Cataldi et al (orgs.). Bioética y humanidades médicas. Buenos Aires: Biblos, 2004.

AQUINO, Tomás de. Summa Theologiae. Citt. S. Th., I, q. 29, a. 3.

ARAÚJO JÚNIOR, João Marcello de. Biotecnologia e direito penal. In: ARAUJO JR, João Marcello de (org.). Ciência e política criminal em honra de Heleno Fragoso. Grupo Brasileiro da Associação Internacional de Direito Penal. Rio de Janeiro: Forense, 1992.

ARNAUD, A. J. (coord.). Dicionário enciclopédico de teoria e sociologia do direito. Rio de Janeiro: Renovar, 1999.

ARRAES, Roosevelt. A extensão dos direitos da personalidade e a situação jurídica do anencéfalo. Disponível em: http://www.uj.com.br/Publicacoes/Doutrinas/default.asp?action=doutrina\&iddoutrina=173 5. Acesso em: 29 jul. 2010. 
ARRIBALZAGA, Eduardo. Transplante de órganos: ¿Puede ser el feto anencefálico um donante potencial? In: Anales de la Facultad de Medicina. Lima: Universidad Nacional Mayor de San Marcos, 2001. n. 4, v. 62.

ASCENSÃO, José de Oliveira. Direito Civil. Teoria Geral. Introdução, as pessoas, os bens. Coimbra: Coimbra Editora, 1997. v. 1.

BARBOZA, Heloísa Helena. A autonomia da vontade e a relação médico-paciente no Brasil. Lex Medicinae - Revista Portuguesa de Direito da Saúde, ano 1, n. 2, p. 5-14, Coimbra, Coimbra Editora, jul.-dez. 2004.

A filiação em face da inseminação artificial e da fertilização in vitro. Rio de Janeiro: Renovar, 1993.

Princípios da bioética e do biodireito. Revista de Bioética, n. 2, p. 209-216, v. 8, Brasília, Conselho Federal de Medicina, 2000.

BAUDOUIN, Jean-Louis; BLONDEAU, Danielle. Éthique de la mort et droit à la mort. Paris: Press Universitaires de France, 1993.

BAUDRY-LACANTINERIE, Gabriel; WAHL, Albert. Traité théorique et pratique de droi civil. Des Successions. Paris: L. Larose \& Forcel, 1905. t. I, n. 139 e 141, v. VII.

BAVIO, Paula Severino. Anencefalia. In: GARAY, Oscar E (org.). Derechos Fundamentales de los Pacientes. Buenos Aires: Ad-Hoc Villela Editor, 2003.

BEAUCHAMP TL, Childress JF. Principles of biomedical ethics. 4. ed. New York: OUP, 1994.

BERUTI, Ernesto. Anencefalia (una visión médica y ética). Disponível em: http://www.revistapersona.com.ar/Persona28/28Beruti.htm. Acesso em: 08 ago. 2011.

BETTI, Emilio. Teoria geral do negócio jurídico. Trad. Fernando Miranda. Coimbra: Coimbra Editora, 1969. v. 2.

BEVILÁQUA, Clóvis. Código Civil dos Estados Unidos do Brazil. Edição histórica. Rio de Janeiro: Editora Rio, 1975.

Teoria geral do direito civil. 3. ed. atualizada por Achilles Beviláqua. Rio de Janeiro: Livraria Franscisco Alves, 1946.

. Teoria geral do direito civil. Ed. rev. e atual. por Caio Mário da Silva Pereira. Rio de Janeiro: Editora Rio, 1975.

BITENCOURT, Cezar Roberto. Manual de direito penal. São Paulo: Saraiva, 2001. v. 2. 
BITTAR, Carlos Alberto. Os direitos da personalidade. 6. ed. rev. atual. e ampl. Rio de Janeiro: Forense Universitária, 2003.

. Os direitos da personalidade. 7. ed. atualizada por Eduardo Carlos Bianca Bittar.

Rio de Janeiro: Forense Universitária, 2006.

BLANCO, Luis Guillermo. Homicidio piadoso, eutanasia, y dignidade humana. Buenos Aires: La Ley, 1997.

BOCK, Gregory; O’CONNOR, Maeve. Human Embryo Research - yes or no? Ciba Foundation Symposium. New York/London: Routledge Publisher/Tavistock Publications, 1986.

BÖCKENFÖRDE, Ernst-Wolfgang. Dignità umana e bioética. A cura di Sara Bignotti., Brescia: Morcelliana, 2010 (Collana "Il pellicano rosso", n. 104).

BONAVIDES, Paulo. Curso de direito constitucional. 10. ed. São Paulo: Malheiros, 2000.

BORGES, Roxana Cardoso Brasileiro. Disponibilidade dos direitos de personalidade e autonomia privada. São Paulo: Saraiva, 2005.

BRASIL, Ângela Bittencourt. Informática jurídica: o ciber direito. Rio de Janeiro: A. Bittencourt Brasil, 2000.

BRASILEIRO FILHO, G. Bogliolo patologia. 6. ed. Rio de Janeiro: Guanabara-Koogan, 2000.

BRUSSINO, Silvia L. Bioética, racionalidad y principio de realidad. Cadernos de Bioética (versão digital), Seção Doutrina. Disponível em: www.bioetica.org/cuadernos/doctrina7.htm. Acesso em: 08 abr. 2011.

BÜCHNER, Luis. Fuerza y matéria. Estudios populares de historia y filosofía naturales. Trad. A. Gómez Pinilla, F. Sempere y Compañía. Disponível em: http://www.filosofia.org/mat/mm185515.htm. Acesso em: 10 mar. 2011.

BUGLIONE, Samantha. Em defesa da vida. Disponível em: http://www.portalbioetica.com.br/adm/artigos/anencefalia_samantha.pdf. Acesso em: 08 ago. 2011. 
BURILlO, Santiago Fernández. El Informe Warnock. Disponível em: www.aceb.org/sfb/mw/w7.htm. Acesso em: 10 mar. 2011.

BUSATO, Paulo César. Tipicidade material, aborto e anencefalia. Revista Eletrônica de Ciências Jurídicas, RECJ 01.04.2004. Disponível em http://www2.mp.ma.gov.br/ampem/artigos/25.\%20Anencefalia_e_\%20aborto.pdf. Acesso em 15 abr. 2011.

CAMPOS, Diogo Leite de. Lições de direitos da personalidade. Coimbra: Coimbra Editora, 1995.

A vida, a morte e a sua indemnização. Separata do Boletim do Ministério da Justiça (n. 365). Lisboa: Ministério da Justiça, 1987.

CANARIS, Claus-Wilhelm. Systemdenken und Systembegriff in der Jurisprudenz. Berlin: Duncker und Humblot, 1983.

CANOTILHO, José Joaquim Gomes. Direito constitucional. Coimbra: Almedina, 1996.

CANTARINO, Carolina. Mulher ou sociedade: quem decide sobre o aborto. Disponível em: http://www.comciencia.br/rportagens/2005/05/05_impr.shtml. Acesso em: 25 ago. 2008 .

CAPEZ, Fernando. Curso de direito penal. Parte especial: dos crimes contra a pessoa. 3. ed. São Paulo: Saraiva, 2004.

CARNELUTTI, Francesco. Teoria geral do direito. Trad. A. Rodriguez Queiróz e Artur Anselmo de Castro. Coimbra: Armênio Armado Editor, 1942.

CARREJO, Simón. Derecho civil. Bogotá: Themis, 1972.

CARVALHO, Orlando de. A teoria geral da relação jurídica - seu sentido e limites. 2. ed. Coimbra: Centelha, 1981.

Policop, 1970.

- Teoria geral da relação jurídica - bibliografia e sumário desenvolvido. Coimbra:

CARVALHO, Virgílio Antônio de. Direito civil: parte geral. 2. ed. Rio de Janeiro: Bedeschi, 1936.

CASTRO, Mônica Neves Aguiar da Silva. Honra, imagem, vida privada e intimidade, em colisão com outros direitos. Rio de Janeiro: Renovar, 2002. 
CERNICCHIARO, Luiz Vicente. Interrupção da gravidez e o anteprojeto de Reforma do Código Penal. Revista Jurídica Consulex, ano VIII, n. 174, Brasília, Consulex, 2004.

CHAUÍ, Marilena. Repressão sexual: essa nossa (des)conhecida. São Paulo: Brasiliense, 1984.

CHAVES, Antônio. Direito à vida e ao próprio corpo (intersexualidade, transexualidade, transplantes). 2. ed. rev. e ampl. São Paulo: Ed. RT, 1994.

Pessoa física ou natural. In: FRANÇA, Rubens Limongi (Org.). Enciclopédia Saraiva do Direito. São Paulo: Saraiva, 1914-1981. v. 58.

CIFUENTES, Santos. El embrión humano. Principio de existencia de la persona. Editorial Astrea, 2002. Disponível em: http://www.astrea.com.ar/libreriavirtual/virtual/autor.jsp?authorCode= 9500. Acesso em: 14 abr. 2007.

COELHO, Walter. Teoria geral do crime. Porto Alegre: Sérgio Antônio Fabris, 1991. v. 1.

COIMBRA, Cícero Galli. Apnéia na morte encefálica. Disponível em: http://www.unifesp.br/dneuro/apnea.htm. Acesso em: 20 jun. 2011.

COOK, Rebecca J. Estimulando a efetivação dos direitos reprodutivos. In: COOK, Rebecca J. et al (org). Reprodução e sexualidade: uma questão de justiça. Porto Alegre: Sérgio Antonio Fabris Editor, 2002.

CORDEIRO, A. Menezes. Tratado de direito civil português I, parte geral. Coimbra: Liv. Almedina, 2004. t. III.

CORONEL, Juan Carlos. Interrupción del embarazo em la anencefalia y la violación. Disponível em: http://www.amfra.org.ar/TRABAJOS/body_trabajos.html. Acesso em: 16 nov. 2008.

CORREIA, Vanessa Cardoso. Wrongful life action: comentário ao Acórdão do Supremo Tribunal de Justiça, de 19 de Junho de 2001. Lex Medicinae - Revista Portuguesa de Direito da Medicina 1, p. 125-131, Coimbra, Coimbra Editora, 2004/2.

CORTEZ, Margarida. Comissões Técnicas de Certificação da Interrupção Voluntária da Gravidez. Lex Medicinae - Revista Portuguesa de Direito da Saúde, ano 1, n. 1, p. 27 31, Coimbra, Coimbra Editora, jan.-jun. 2004. 
CORTIANO JÚNIOR, Eroulths. Alguns apontamentos sobre os chamados diretos da personalidade. In: FACHIN, Luiz Edson (Coord.). Repensando fundamentos do direito civil brasileiro. Rio de Janeiro: Renovar, 1998.

Direitos da personalidade: direito à vida, ao próprio corpo e ao cadáver. 1993, 150 f., Dissertação (Mestrado em Direito) - Faculdade de Direito, Universidade Federal do Paraná, Curitiba, 1993.

COSTA, José de Faria. O direito penal económico e as causas implícitas de exclusão da ilicitude. In: CORREIA, Eduardo et al (orgs.). Direito penal económico e europeu: textos doutrinários. Problemas gerais. Coimbra: Coimbra Editora, 1998. v. 1.

COSTA, Sérgio; DINIZ, Débora. Bioética: ensaios. Brasília: SIF, 2001.

COUTINHO, Luiz Augusto. Aborto nos caos de anencefalia: crime ou inexigibilidade de conduta diversa. Disponível em: http://www.buscalegis.ufsc.br/arquivos/aborto_anencefalia_17-03.htm. Acesso em: 15 set. 2007.

CRETELLA JR, José. Curso de direito romano. 22. ed. Rio de Janeiro: Forense, 1999.

CRUZ, Manuel Jorge Santos da Silva. O conceito de morte cerebral numa perspectiva ética. 2003, 140 f., Dissertação (Mestrado em Bioética e Ética Médica) - Faculdade de Medicina da Universidade do Porto. Porto, 2003.

CRUZ, Peter De. Comparative healthcare law. London: Routledge-Cavendish Publisher, 2001.

CUNHA, Alexandre dos Santos. A normatividade da pessoa humana: o estudo jurídico da personalidade e o Código Civil de 2002. Rio de Janeiro: Forense, 2005.

CUNHA, Antônio Geraldo da. Dicionário etimológico da língua portuguesa. 3. ed. Rio de Janeiro: Lexikon Editora Digital, 2007.

CYPEL, S.; DIAMENT, A. Malformações cerebrais. Rio de Janeiro: Guanabara-Koogan, 1977.

Neurologia infantil. 3. ed. São Paulo: Atheneus, 1996.

DA COSTA, Helena Regina Lobo. Mulher e direito penal. São Paulo: Forense, 2007.

DABIN, Jean. Le droit subjectif. Paris: Dalloz, 1952. 
DANTAS, San Tiago. Programa de direito civil. 2. ed. Rio de Janeiro: Ed. Rio, 1979.

DE CUPIS, Adriano. I diritti della personalità. Milano: Giuffrè, 1982.

. Os direitos da personalidade. Trad. Adriano Vera Jardim e Antônio Miguel

Caeiro. Lisboa: Livraria Morais, 1961.

. Os direitos da personalidade. Campinas: Romana Jurídica, 2004.

Riservatezza e segretto (Diritto a). In: AZARA, Antonio; EULA, Ernesto (a cura

di). Novissimo digesto italiano. 3. ed. Torino: UTET, 1969. v. 16.

DE PAULO, Antônio (org). Pequeno dicionário jurídico. Rio de Janeiro: Ed. DP\&A, 2002.

DELmanto, Celso et al. Código Penal comentado. 6. ed. Rio de Janeiro: Renovar, 2002.

DIAS, Jorge de Figueiredo. Comentário conimbricense do Código Penal. Parte especial. Coimbra: Coimbra Editora, 1999. t. I.

DIAS, Maria Berenice. Manual de direito das famílias. 5. ed. São Paulo: Ed. RT, 2009.

DINIZ, Débora; PARANHOS, Fabiana. Anencefalia: o pensamento brasileiro em sua pluralidade. Anais. Brasília: Instituto de Bioética, Direitos Humanos e Gênero, out. 2004. p. 91. Disponível em: http://www.anis.org.br/Arquivos/Textos/pluralidade_final.pdf. Acesso em 02 ago. 2011.

DINIZ, Maria Helena. Compêndio de introdução à ciência do direito. São Paulo: Saraiva, 1995.

. Curso de direito civil brasileiro: teoria geral do direito civil. 18. ed. atual.São Paulo: Saraiva, 2002. v. 1.

Curso de direito civil brasileiro: teoria geral do direito civil. 20. ed., rev. e aum. São Paulo: Saraiva, 2003. v. 1. 2004. v. 6.

Curso de direito civil brasileiro: direito das sucessões. 18. ed. São Paulo: Saraiva, 1994.

Lei de Introdução ao Código Civil brasileiro interpretada. São Paulo: Saraiva, O estado atual do biodireito. São Paulo: Saraiva, 2001.

DOMÍnguEZ, Andrés Gil. La Suprema Corte de la Provincia de Buenos Aires y el parto inducido de una vida humana en formación: de cuando las convicciones personales se imponen a los valores constitucionales en el ejercicio de la jurisdicción constitucional. Buenos Aires: La Ley, 2001. 
DONOSO, Denis. Alimentos gravídicos. Aspectos materiais e processuais da Lei 11.804/2008. Jus Navigandi, Teresina, ano 13, n. 2028, 19 jan. 2009. Disponível em: http://jus2.uol.com.br/doutrina/texto.asp?id=12219. Acesso em: 28 jul. 2009.

DWORKIN, Ronald. Levando os direitos a sério. Trad. Nelson Boeira. 2. ed. São Paulo: Martins Fontes, 2007. 2003.

O império do direito. Trad. Jefferson Luiz Camargo. São Paulo: Martins Fontes,

ECHTERHOFF, Gisele. O princípio da dignidade da pessoa humana e a biotecnologia. In: MEIRELLES, Jussara Maria Leal de (coord.). Biodireito em discussão. Curitiba: Juruá, 2008.

ENGELHARDT, H. Tristram. Los fundamentos de la Bioética. Barcelona: Paidos, 1995.

ENNECCERUS, Ludwig. Tratado de derecho civil. Barcelona: Bosch, 1947. v. I.

ESPINOLA, Eduardo. Sistema do direito civil brasileiro. 4. ed. Rio de Janeiro: Conquista, 1961. v. 2.

Sistema do direito civil brasileiro. Rio de Janeiro: Rio, 1977.

FACHIN, Luiz Edson. Teoria crítica do direito civil. 2. ed. Rio de Janeiro: Renovar, 2003.

FACHIN, Zulmar Fachin. A proteção jurídica da imagem. São Paulo: Celso Bastos Editor/Instituto Brasileiro de Direito Constitucional, 1999.

FARIAS, Cristiano Chaves de. Direito civil: teoria geral. Rio de Janeiro: Lumen Juris, 2005.

FAYT, Carlos S. Los derechos humanos y el poder mediático, político y económico. Su mundialización em el siglo XXI. Buenos Aires: La Ley, 2011.

FERNANDES, Luis Alberto de Carvalho. Teoria geral do direito civil. 2. ed. Lisboa: Lex, 1995. v. 1.

FERRAZ, Sérgio. Manipulações biológicas e princípios constitucionais: uma introdução. Fabris: Porto Alegre, 1991. 
FERREIRA, A. B. H. Dicionário Aurélio básico da língua portuguesa. Rio de Janeiro: Nova Fronteira, 1995.

FONSECA, Antonio Cezar Lima da. Dos alimentos gravídicos - Lei 11.804/2008. Revista IOB de Direito de Família, n. 51, v. 9, p. 7-17, dez.-jan. 2009.

FOST, Norman. Organs from anencephalic infants: an idea whose time has not yet come. The Hastings Center Report, n. 5, v. 18, p. 5-10, oct.-nov. 1988. Disponível em: http://www.ncbi.nlm.nih.gov/pubmed/3225191. Acesso em: 08 ago. 2011.

FRAGOSO, Heleno Cláudio. Lições de direito penal. Parte especial. 7. ed. Rio de Janeiro: Forense, 1983. n. 80.

FRANÇA, Rubens Limongi. Fato jurídico. In: FRANÇA, Rubens Limongi (coord.). Enciclopédia Saraiva do direito. Saraiva: São Paulo, 1977. vol 36. Instituições de direito civil. São Paulo: Saraiva, 1988. Instituições de direito civil. 4. ed. atual. São Paulo: Saraiva, 1996. . Instituições de direito civil. 5. ed. São Paulo: Saraiva, 1999. Manual de direito civil. 3. ed. São Paulo: Ed. RT, 1975. Manual de direito civil. 4. ed. São Paulo: Ed. RT, 1980. v. 1.

FREITAS, Ana Clélia de et al. Existe aborto de anencéfalos? DireitoNet, São Paulo, 18 mar. 2005. Disponível em: http://www.direitonet.com.br/artigos/exibir/1969/Existe-abortode-anencefalos. Acesso em: 02 set. 2008.

FREITAS, Teixeira Augusto de. Consolidação das leis civis. 3. ed. Rio de Janeiro: H Garnier, 1896.

GARAY, Oscar E. Derechos fundamentales de los pacientes. Buenos Aires: Ad-Hoc Villela Editor, 2003.

GARRAFA, Volnei. O mercado de estruturas humanas. Disponível em: http://www.portalmedico.org.br/revista/bio2v1/mercado.html. Acesso em: 21 set. 2009.

GEDIEL, José Antônio Peres. Os transplantes de órgãos e a invenção moderna do corpo. Curitiba: Moinho do Verbo, 2000.

GEORG, Faerber. Wrongful Life: Die Deliktsrechtliche Verantwortlichkeit des Arztes Dem Kind Gegenuber Eine Rechtsvergleichende Darstellung des Amerikanischen, Britischen und Deutschen Rechts, Verlag: Mainz, G, 1988. 
GHERARDI, Carlos. Muerte cerebral: una mirada crítica y reflexiva, civil y penal. Buenos Aires: La Ley, 2001.

; GHERARDI, Natalia. La medicina defensiva: un problema social. In: SOROKIN, Patricia (coord.). Bioética: entre utopías y desarraigos. Buenos Aires: Ad-Hoc, 2002.

; KURLAT, Isabel. Anencefalia e interrupción del embarazo. Nueva Doctrina Penal, Separata, 2000-B.

GHIRARDI, Olsen A. La persona humana antes del nacimiento. Anais da Academia Nacional de Direito e Ciências Sociais de Córdoba, t. XXX, v. I, Córdoba, 1991.

GIBERTI, Eva. Anencefalia y daño psíquico en la madre. Disponível em: http://www.aabioetica.org/anac.HTM. Acesso em: 03 abr. 2009.

GIORDANI, Mário Curtis (trad.). O Código Civil à luz do Direito Romano. 2. ed. Rio de Janeiro: Lumen Juris, 1996.

GIZBERT-STUDNICKI, Tomasz; PIETRZYKOWSKI, Tomasz. Positivismo blando y la distinción entre Derecho y moral. Doxa, Alicante: Universidad de Alicante, 2004. N. 27.

GLOVER, J.; HOLBROOK, P.R. Ethical considerations. In: HOLBROOK, P.R. (org.). Textbook of pediatric critical care. Philadelphia: W. B. Saunders, 1993.

GOFFMAN, Erving. The presentation of the self in everiday life. New York: Doubleday, 1959.

GOGLIANO, Daisy. Direitos privados da personalidade. 1982, 426 p. Dissertação (Mestrado em Direito) - Faculdade de Direito da Universidade de São Paulo, São Paulo, 1982. 1993.

Pacientes terminais - morte encefálica. Bioética, n. 2, p. 145-156, v. 1, Brasília,

GOMES, Luiz Flávio. Aborto anencefálico: exclusão da tipicidade material. Disponível em: http://jus2.uol.com.br/doutrina/texto.asp?id=8561. Acesso em: 22 nov. 2007.

. Nem todo aborto é criminoso. Revista Síntese de Direito Penal e Processual Penal, ano V, n. 28, p. 35-36, out.-nov. 2004.

GOMES, Mariângela Gama de Magalhães. Descriminalizar é salvar vidas. Boletim IBCCrim, n. 151, v. 13, São Paulo, jun. 2005. 
GOMES, Orlando. Introdução ao direito civil. 2. ed. Rio de Janeiro: Forense, 1965. Introdução ao direito civil. 13. ed. Rio de Janeiro: Forense, 1998. Introdução ao direito civil. 18. ed. Rio de Janeiro: Forense, 2001.

GONÇALVES, Carlos Roberto. Direito civil brasileiro: parte geral. 3. ed. São Paulo: Saraiva, 2006. v. 1.

GONÇALVES, Gabriel António Órfão. Da personalidade jurídica do nascituro. Revista da Faculdade de Direito da Universidade de Lisboa, n. 1, v. XLI, Lisboa, Combra Editora, 2000 .

GONÇALVES, Teresa. Serão pessoas? Disponível em: http://www.portaldafamilia.org/artigos/artigo543.shtml. Acesso em: 27 jul. 2011.

GRECO, Rogério. Curso de direito penal. Parte especial. 7. ed. rev. e atual. Niterói: Impetus, 2006.

GURGEL, Ângela M Rodrigues O P. Aborto - Agressão a vida ou liberdade de escolha? Série: Artigos sobre os temas CF 1988, escritos para o Caderno Expressão da Gazeta do Oeste. Disponível em: http://www.recantodasletras.com.br/ensaios/1081520. Acesso em: 06 abr. 2010.

HABERMAS, Jürgen. Fatti e norme - contributi a teoria discorsiva del diritto e della democrazia. Milano: Edizioni Guerini, 1996.

HABIB, Sérgio. O aborto por anencefalia e a cassação da liminar do Ministro Marco Aurélio. Revista Jurídica Consulex, ano VIII, n. 188, Brasília, Consulex, 2004.

HARE, Richard. Essays on Bioethics. Oxford: Oxford University Press, 1993.

HART, Herbert Lionel Adolphus. O conceito de Direito. Pós-escrito editado por Penelope A Bulloch e Joseph Raz. Trad. A. Ribeiro Mendes. 3. ed. Lisboa: Fundação Calouste Gulbenkian, 2001.

HERMITTE, Marie A. L'embryon. Conferência realizada em 27 de junho de 2002 no Seminário "Sujets et objets de droit dans les lois de bioethique et leur revision". Centro Franco Argentino de Altos Estúdios, UBA. 
HOESCHL, Hugo César. O conflito e os direitos da vida digital. Disponível em: http://www.mct.gov.br/legis/Consultoria_Juridica/artigos/vida_digital.htm. Acesso em: 15 maio 2009.

HONDIUS, Ewoud. The Kelly Case - Compensation for Undue Damage for Wrongful Treatment. In: GEVERS, J. K. M.; HONDIUS, E. H.; HUBBEN, J. H. (orgs.). Health, law, human rights and the biomedicine convention: essays in honour of Henriette Roscam Abbing. Leiden, Boston: Nijhoff, 2005.

HORTA, Márcio Palis. Eutanásia - Problemas éticos da morte e do morrer. Bioética, Brasília, n. 1, p. 27-33, v. 7, 1999.

HOUAISS, Antônio; VILLAR, Mauro de Salles. Mindicionário Houaiss da Língua Portuguesa. 2. ed. rev. e atual. Rio de Janeiro: Objetiva, 2004.

HUNGRIA, Nélson. Comentários ao Código Penal. 5. ed. Rio de Janeiro: Forense, 1979. v. V.

IWASSO, Simone; LEITE, Fabiane. Junta diz que Marcela não era anencéfala. O Estado de São Paulo. Disponível em: http://www.ccr.org.br/a_noticias_detalhes.asp?cod_noticias=4041. Acesso em: 05 ago. 2011.

JESCHECK, Hans-Heinrich. Tratado de derecho penal. Parte general. Granada: Editorial Comares, 1993.

JESUS, Damásio E. de. Direito penal. 2. ed. ampl. e atual. São Paulo: Saraiva, 1980. v. 1. . Direito penal. 19. ed. São Paulo: Saraiva, 1997. v. 2.

JUNGES, José Roque. Bioética, perspectivas e desafios. São Leopoldo: Unisinos, 1999.

KANT, Immanuel. Metafísica dos costumes. Bauru: Edipro, 2003.

Fundamentação da metafísica dos costumes e outros escritos. São Paulo: Martin Claret, 2004.

KIMURA, Maria Regina Trippo. As técnicas biomédicas - A vida embrionária e o patrimônio genético humano - À luz da regra da proporcionalidade penal. 2006, 324 p. Tese (Doutorado em Direito) - Pontifícia Universidade Católica de São Paulo, 2006. 
KIPPER, Délio José. Breve história da ética em pesquisa. Revista da AMRIGS, 54 (2), pp. 224-228, Porto Alegre, abr.-jun. 2010.

; HOSSNE, Williarn Saad. Caso clínico. Bioética, 1998, v. 6, p. 6. Disponível em: http://www.portalmedico.org.br/revista/bio2v6/casoclinico.htm. Acesso em: 15 abr. 2009.

KOPPERNOCK, Martin. Das Grundrecht auf bioethische Selbstbestimmung. Zur Rekonstruktion des allgemeinen Persönlichkeitsrechts. Baden-Baden: Nomos Verlag, 1997.

KOTTOW, Miguel H. Introducción a la bioética. 2. ed. Santiago: Mediterráneo, 2005.

LABOMBARDA, Pablo Martín. El derecho y la bioética frente a la anencefalia. La Plata: Libreria Editora Platense, 2009.

LEMIERE, R. J.; BECKWITH, J. B.; WARKANY, J. Anencephaly. New York: Raven Press, 1978.

LIMA, Carolina Alves de Souza Lima. Aborto e anencefalia - direitos fundamentais em colisão. Curitiba: Juruá, 2008.

LIMA, João Franzen de. Curso de direito civil brasileiro. Rio de Janeiro: Forense, 1984. v. 1.

LINDON, Raymond. Dictionnaire juridique: les droits de ia personnalite. Paris: Dalloz, 1983.

LISBOA, Roberto Senise. Manual de direito civil. 3. ed. São Paulo: Ed. RT, 2004. v. 1.

LOPEZ, Teresa Ancona. O dano estético - Responsabilidade civil. 3. ed. rev., ampl. e atual. São Paulo: Ed. RT, 2004.

LORENZETTI, Ricardo Luis. Fundamentos do direito privado. São Paulo: Ed. RT, 1998.

MAIA, Lauro Augusto Moreira. Novos Paradigmas do Direito Civil. Curitiba: Ed. Juruá, 2007. 
MAIA, Manoel Cláudio da Motta. Novos aspectos da cirurgia moderna. Revista Hospital Rio, n. 74, v. 3, p. 669-687, , Rio de Janeiro, SINDHERJ, FEHERJ, AHCRJ, set. 1968.

MANREZA, Luiz Alcides. Morte clínica. Revista da Associação Médica Brasileira, v. 33, n. 5/6, São Paulo, AMB, 1987.

MARANHÃO, Odon Ramos. Curso básico de medicina legal. 4. ed. rev. e ampl. São Paulo: Ed. RT, 1990.

Manual de sexologia médico-legal. São Paulo: Ed. RT, 1972.

MARTÍNEZ, Stella Maris. Manipulação genética e direito penal. São Paulo: IBCCrim, 1998.

MARTINS, Flademir Jerônimo Belinati. Dignidade da pessoa humana: princípio constitucional fundamental. Curitiba: Juruá, 2003.

MARTINS, Humberto Eustáquio Soares. Dissolução da sociedade conjugal no Código civil de 2002: separação consensual judicial e extrajudicial. Disponível em: http://bdjur.stj.gov.br/xmlui/bitstream/handle/2011/24454/Dissolu\%C3\%A7\%C3\%A3o_S ociedade_Conjugal.doc.pdf. Acesso em: 20 jul. 2011.

MARTINS, Ives Gandra da Silva. O Supremo e o homicídio uterino. Jornal do Brasil, 15 jul. 2004.

MASSIMILIANO, Monti. Fecondazione, embrione e fasi iniziali della gravidanza. Disponível em: http://www.ginecolink.net/percorso_non_medici/fecondimpian.htm. Acesso em: 22 abr. 2010.

MATA-MACHADO, Edgar de Godoi da. Elementos de teoria geral do direito. 4. ed. Belo Horizonte: UFMG, 1995.

MATTOS, Luiza Thereza Baptista de. A proteção ao nascituro. Revista de Direito Civil, Imobiliário, Agrário e Empresarial, 14(52): 30-7, São Paulo, abr.-jun. 1990.

MEDINA, Avelino. Distúrbios da consciência: coma. Rio de Janeiro: Cultura Médica, 1984.

MEIRELLES, Jussara Maria Leal de (coord.). Biodireito em discussão. Curitiba: Ed. Juruá, 2008. 
O ser e o ter na codificação civil brasileira: do sujeito virtual à clausura patrimonial. In: FACHIN, Luiz Edson (coord.). Repensando fundamentos do direito civil brasileiro. Rio de Janeiro: Renovar, 1998.

; TEIXEIRA, Eduardo Didonet. Consentimento livre, dignidade e saúde pública: o paciente hipossuficiente. In: RAMOS, Carmem Lúcia Nogueira et al (orgs.). Diálogos sobre direito civil: construindo uma racionalidade contemporânea. Rio de Janeiro: Renovar, 2002.

MELLO, Maria Tereza Leopardi. Direito e economia em Weber. Revista Direito-GV, n. 2, v. 2, 2006.

MESSINEO, Francesco. Istituzioni di diritto privato secondo la nuova legislazione. Padova: A. Milani, 1939.

MESTIERI, João. Embriões. Consulex, n. 32, v. 1, Brasília, ago. 1999.

MILL, John Stuart. Sobre la libertad. Trad. Gregório Cantera. Madri: Biblioteca Edaf, 2004.

MINAHIM, Maria Auxiliadora. O direito penal na regulação da vida e da morte ante a biotecnologia. 2005, 239 p. Tese (Doutorado em Direito) - Faculdade de Direito, Universidade Federal do Paraná, Curitiba, 2005.

MIRABETE, Júlio Fabbrini. Código Penal interpretado. 5. ed. São Paulo: Atlas, 2005. . Manual de direito penal. 16. ed. São Paulo: Atlas, 2000. v. II.

MIRANDA, Jorge. A Constituição Portuguesa e a dignidade da pessoa humana. Revista de Direito Constitucional e Internacional, n. 45, p. 81-91, v. 11, São Paulo, out.-dez. 2003.

Manual de direito constitucional. 3. ed. Coimbra: Coimbra Editora, 2000. t. IV.

MIRANDA, Pontes de. Fontes e evolução do direito civil brasileiro. 2. ed. Rio de Janeiro: Forense, 1981.

Tratado de direito privado. Rio de Janeiro: Borsoi, 1971. t. VII.

Tratado de direito privado. Campinas: Bookseller, 2000.

Tratado de direito privado. t. I. Disponível em: http://200.255.167.162/pesquisa/pdf_livros/pontes_de_miranda_tratado_de_direito_privad o/tratado_de_direito_privado_tomo1.pdf. Acesso em: 10 ago. 2011.

MONTEIRO, Washington de Barros. Curso de direito civil: parte geral. 37. ed. São Paulo: Saraiva, 2000. v. 1.

Curso de direito civil - Parte Geral. 39. ed. Saraiva: São Paulo, 2003. v. 1. 
MONTENEGRO, Karla Bernardo. Início da Vida no STF. Disponível em: http://www.ghente.org/entrevistas/inicio_da_vida.htm. Acesso em: 13 abr. 2010.

MONTORO, André Franco. Introdução à ciência do Direito. 24. ed. São Paulo: Ed. RT, 1997.

Introdução à ciência do direito. 25. ed. São Paulo: Ed. RT, 2000.

MORAES, Walter. Direitos da personalidade, estado da matéria no Brasil. CHAVES, Antonio (coord.). Estudos de direito civil. São Paulo: Ed. RT, 1979.

O problema da autorização judicial para o aborto. Revista de Jurisprudência do

Tribunal de Justiça do Estado de São Paulo, ano 20, p. 24-25, v. 99, mar.-abr. 1986.

MORAES, Alexandre de Direito constitucional. 13. ed. São Paulo: Atlas, 2003. Direito constitucional. 19. ed. São Paulo: Atlas, 2006.

MORAITIS, Anastasios. When Childbirth becomes Damage: a comparative overview of "wrongful birth" and "wrongful life" claims. Lex Medicinae - Revista Portuguesa de Direito da Saúde, ano 4, n. 8, p. 37-58, Coimbra, Coimbra Editora, jul.-dez. 2007.

MORATO, Eric Grossi. Morte encefálica: conceitos essenciais, diagnóstico e atualização. Revista Médica, p. 227-236, 2009; 19(3), p. 228. Disponível em: http://www.medicina.ufmg.br/rmmg/index.php/rmmg/article/viewFile/164/147. Acesso em: 06 maio 2011.

MORELLI, Mariano G.. Derechos humanos y argumentaciones en el caso de la anencefalia. Consideraciones jurídico-filosóficas con referencia a um caso judicial. Bioetica y Bioderecho, n. 6, pp. 23-49, Fundación para las Investigaciones Jurídicas, 2001. Disponível em: http://www.cartapacio.edu.ar/ojs/index.php/byb/article/view/259/167. Acesso em: 23 set. 2010.

MORRISON, Wayne. Filosofia do direito - dos gregos aos pós-moderno. São Paulo: Martins Fontes, 2006.

MUÑOZ, Daniel Romero; FORTES, Paulo Antônio Carvalho. O princípio da autonomia e o consentimento livre e esclarecido. In: COSTA, Sergio Ibiapina Ferreira et al (orgs.). Iniciação à bioética. Brasília: Conselho Federal de Medicina, 1998.

MUTO, Eliza; NARLOCH, Leandro. Quando a vida começa? Se começa na fecundação, várias pesquisas com células-tronco têm de ser proibidas já. Se começa com a atividade 
cerebral, 60\% dos abortos devem ser legalizados. Revista Super Interessante. Ed. 219, nov. 2005.

NALINI, José $\mathrm{R}$ nato. A gestante tem o direito de interromper a gravidez de feto anencéfalo? Jornal do Advogado, OAB-SP, edição de agosto de 2004. Disponível em: http://www.oabsp.org.br/jornal/ e http://www.portaldafamilia.org/artigos/artigo271.shtml. Acesso em: 02 ago. 2011.

NERY JUNIOR, Nelson; NERY, Rosa Maria de Andrade. Código Civil anotado. 2. ed. São Paulo: Ed. RT, 2003.

OLIVEIRA JUNIOR, José Alcebíades. Teoria jurídica e novos direitos. Rio de Janeiro: Lumen Juris, 2000.

OLIVEIRA, Simone Born. Da bioética ao biodireito - manipulação genética \& dignidade humana. Curitiba: Juruá, 2002.

ORGAZ, Alfredo. Código Civil y leyes complementarias. Comentado, anotado y concordado. Coord. Augusto C. Belluscio. Buenos Aires: Astrea, 1978. t. I.

PACHECO, Pedro Mercado. El Análisis Económico del Derecho- una reconstrucción teórica. Madrid: Cento de Estudios Constitucionales, 1994.

PAIM, Antônio. Problemática do culturalismo. Porto Alegre: PUC/RS, 1995 (Coleção "Filosofia", 24).

PASOLD, Cesar Luiz. Direito à saúde. Sequiência: Estudos Jurídicos e Políticos, n. 15, Florianópolis, dez. 1987.

PENNA, Maria Lúcia Fernandes. Anencefalia e morte cerebral (neurológica). Physis. Rev. Saúde Coletiva, Rio de Janeiro, v. 15, n. 1, p. 95- 106, jan.-jun. 2005. Disponível em: http://dx.doi.org/10.1590/S0103-73312005000100005 e http://www.scielo.br/scielo.php?pid=S0103-73312005000100006\&script=sci_arttext. Acesso em: 08 ago. 2011.

PEREIRA, Caio Mario da Silva. Direito civil: alguns aspectos da sua evolução. Rio de Janeiro: Forense, 2001.

Instituições de direito civil. 3. ed. Rio de Janeiro: Forense, 1971. v. 1.

Instituições de direito civil. 18. ed. Rio de Janeiro: Forense, 1996. v. 1.

Instituições de direito civil. 19. ed. rev. e atual. Rio de Janeiro: Forense, 2002. v.

1.

Instituições de direito civil. 21. ed. Rio de Janeiro: Forense, 2006. v. 1. 
Instituições de direito civil. 22. ed. Rio de Janeiro: Forense, 2007. v. 1.

Instituições de direito civil. Direito das sucessões. 3. ed. Rio de janeiro: Forense, 1980. v. 6.

Instituições de direito civil. Direito das sucessões. 16. ed. Rio de Janeiro: Forense, 2007. v. 6.

PEREIRA, Virgílio de Sá. Manual do Código Civil brasileiro. Rio de Janeiro: Jacintho Ribeiro dos Santos, 1929.

PERLINGIERI, Pietro. Perfis do direito civil. Introdução ao direito civil constitucional. Trad. Maria Cristina De Cicco. 2. ed. Rio de Janeiro: Renovar, 2002.

PINTO, Eduardo Vera-Cruz. Considerações genéricas sobre os direitos da personalidade. II JORNADA DE DIREITO CIVIL, Centro de Estudos Judiciários do Conselho da Justiça Federal, 17 a 25 nov. 2003, TRF-5. ${ }^{a}$ Reg., STJ e TRF-4. ${ }^{a}$ Reg. Disponível em: http://www.cjf.jus.br/revista/numero25/artigo09.pdf. Acesso em: 02 out. 2009.

PINTO, Paulo Mota. Indemnização em caso de "nascimento indevido" e de "vida indevida" ("wrongful birth" e "wrongful life"). Lex Medicinae - Revista Portuguesa de Direito da Saúde, ano 4, n. 7, p. 5-25, Coimbra, Coimbra Editora, jan.-jun. 2007.

PIVA, Jefferson Pedro; CARVALHO, Paulo R. Antonacci. Considerações éticas nos cuidados médicos do paciente terminal. Bioética, n. 2, p. 129-138, v. 1, Brasilia, 1993.

PONTES, Manuel Sabino. A anencefalia e o crime de aborto: atipicidade por ausência de lesividade. Jus Navigandi, Teresina, ano 10, n. 859, 9 nov. 2005. Disponível em: http://jus.uol.com.br/revista/texto/7538. Acesso em: 12 jul. 2011.

PRADO, Luis Regis. Curso de direito penal brasileiro - Parte Geral. 6. ed. São Paulo: Ed. RT, 2006. v. 1.

. Curso de direito penal brasileiro. 5. ed. São Paulo: Ed. RT, 2006. v. 2.

PRADO, Simone Marcussi de Almeida. O direito à vida mesmo que por um dia - o aborto de anencéfalo. Disponível em: http://www.portaldafamilia.org/artigos/artigo706.shtml. Acesso em: 27 jun. 2011.

RABINOVICH-BERKMAN, Ricardo D.. Una aproximación a la problemática jurídica de la anencefalia. Disponível em: http://www.revistapersona.com.ar/Persona26/26Rabinovich.htm. Acesso em: 15 abr. 2011. 
RAMOS, Dalton Luiz de Paula. A vida humana começa na fecundação. Disponível em: http://blog.cancaonova.com/felipeaquino/2007/04/24/\%C2\%ABa-vida-humana-comecana-fecundacao\%C2\%BB/. Acesso em: 06 abr. 2010.

RAO, Vicente. O direito e a vida dos direitos. 5. ed. anot. e atual. por Ovídio Rocha Barros Sandoval. São Paulo: Ed. RT, 1999.

RAPOSO, Vera Lúcia. Direitos reprodutivos. Lex Medicinae - Revista Portuguesa de Direito da Saúde, ano 2, n. 3, Coimbra: Coimbra Editora, jan.-jun. 2005.

REALE, Miguel. Experiência e cultura: para a fundação de uma teoria geral da experiência. 2. ed. Campinas: Bookseller, 2000.

REGIS, A. H. de P. Início da vida humana e da personalidade jurídica: questões à luz da bioética. Jus Navigandi. Disponível em: http://jus2.uol.com.br/doutrina/texto.asp?id=6462. Acesso em: 22 mar. 2008.

RIBEIRO, Diaulas Costa. Antecipação terapêutica do parto: uma releitura jurídico-penal do aborto por anomalia fetal no Brasil. In: DINIZ, Débora; RIBEIRO, Diaulas Costa (orgs.). Aborto por anomalia fetal. Brasília: Letras Livres, 2004 (Coleção "Radar", n. 1). RÍO, José Manuel Lete Del. Derecho de la persona. 4. ed. Madri: Tecnos, 2000.

RIZZARDO, Arnaldo. Parte geral do Código Civil. 2. ed. Rio de Janeiro: Forense, 2003. Parte geral do Código Civil: Lei 10.406, de 10.01.2002. 3. ed. Rio de Janeiro: Forense, 2005.

RODRIGUES, Rafael Garcia. A pessoa e o ser humano no novo Código Civil. In: TEPEDINO, Gustavo (coord.). A parte geral do novo Código Civil: estudos na perspectiva civil-constitucional. 2. ed. rev. e atual. Rio de Janeiro: Renovar, 2003.

RODRIGUES, Silvio. Direito Civil - Parte Geral. 34. ed. São Paulo: Saraiva, 2007. v. 1.

ROMEO-CASABONA, Carlos María. La Constituición Europea, un núcleo de los derechos humanos de la Medicina y la Biología. Lex Medicinae - Revista Portuguesa de Direito da Saúde, ano 2, n. 3, Coimbra, Coimbra Editora, jan.-jun. 2005.

ROSPIGLIOSI, Enrique Varsi. Derecho Genético. 4ª edição. Lima: Gijley, 2001.

ROXIN, Claus. Derecho penal. Parte general. Madrid: Civitas, 1997. t. I, § 14, IV. 
A proteção da vida humana através do Direito Penal. Disponível em: http://www.mundojuridico.adv.br/sis_artigos/artigos.asp?codigo=134. Acesso em: 14 abr. 2010.

RUGGIERO, Roberto. Instituições de direito civil. Trad. Ary dos Santos. Saraiva: São Paulo, 1934. v. 1.

RUMJANEK, Franklin D. Origem da vida, por YI, Wang Pei. Disponível em: http://www.olharvital.ufrj.br/ant/2005_12_01/materia_faceseinterfaces.htm. Acesso em: 14 abr. 2010.

RUY, Kelly Aquotti. Qual a origem do princípio de Saisine? Disponível em: http://www.lfg.com.br/public_html/article.php?story=20090211091038217. Acesso em: 19 jul. 2011.

SÁ, Maria de Fátima Freire de. Direito de morrer: eutanásia, suicídio assistido. Belo Horizonte: Del Rey, 2001.

SAMBRIZZI, Eduardo A. Derecho y eugenesia. Buenos Aires: Educa, 2004.

SANCHES, Mônica Torres Lopes. O testemunho de Mônica, mãe de Giovana, anencéfala. Disponível em: http://www.providaanapolis.org.br/index1.htm. Acesso em: 28 jul. 2011.

SANTOS, Maria Celeste Cordeiro dos. O equilíbrio do pêndulo. A Bioética e a Lei. Implicações médico-legais. São Paulo: Ícone, 1998.

SANTOS, Washington dos. Dicionário jurídico brasileiro. Belo Horizonte: Del Rey, 2001.

SARLET, Ingo Wolfgang. A eficácia dos direitos fundamentais. Porto Alegre: Livraria do Advogado, 1998.

A eficácia dos direitos fundamentais. 6. ed. rev. atual. e ampl. Porto Alegre: Livraria do Advogado, 2006.

Dignidade da pessoa humana e direitos fundamentais na Constituição Federal de 1988. 3. ed. Porto Alegre: Livraria do Advogado, 2004.

SARTRE, Jean Paul. El existencialismo es un humanismo. 2. ed. Buenos Aires: Losada, 2002.

SCHAEFER, Fernanda. Bioética, biodireito e direitos humanos. In: MEIRELLES, Jussara Maria Leal de (coord.). Biodireito em discussão. Curitiba: Juruá, 2008. 
SCHINESTSCK, Clarissa Ribeiro. As pesquisas com células-tronco embrionárias: o direito à vida digna ou o direito à dignidade do embrião in vitro? Revista eletrônica da Faculdade de Direito da PUC-SP. Disponível em: http://revistas.pucsp.br/index.php/red/article/download/522/513. Acesso em: 25 set. 2008.

SEGRE, Marco. Eutanásia: aspectos éticos e legais. Revista da Associação Médica Brasileira, v. 32, n. 7/8, p. 141-142, São Paulo, AMB, 1986.

; HOSSNE, William Saad. O aborto e o transplante de tecido fetal. Bioética, n. 1, Brasília, Conselho Federal de Medicina, 1994, v. 2. Disponível em: www.portalmedico.org.br. Acesso em: 16 abr. 2009.

SÉVE, Lucien. Para uma crítica da razão bioética. Lisboa: Instituto Piaget, 1994.

SGRECCIA, Elio. Manual de Bioética. I - Fundamentos e ética biomédica. 2. ed. São Paulo: Loyola, 2002.

SHAKESPEARE, William. Hamlet. Ato III. Rio de Janeiro: Objetiva, 2003.

SHEWMON, D. A. Anencephaly: selected medical aspects. New York: Hastings Center Report, 1988. n. 5, v. 18.

SILVA, De Plácido e. Dicionário jurídico. 15. ed. rev. e atual. por Nagib Slaibi Filho. Rio de Janeiro: Forense, 1999.

SILVA, José Afonso da. Curso de direito constitucional positivo. 20. ed. São Paulo: Malheiros, 2002.

. Curso de direito constitucional positivo. 27. ed. São Paulo: Malheiros, 2006. Curso de direito constitucional positivo. 30. ed. São Paulo: Malheiros, 2008.

SIMAS FILHO, Fernando. A prova na investigação de paternidade. 5. ed. rev. e ampl. Curitiba: Juruá, 1996.

SIMINOFF, Laura A. The dead donor rule: not dead yet. The American Journal of Bioethics, n. 1, v. 3, p. 30-30, winter 2003. 
SINGER, Peter. Ética prática. Trad. Álvaro Augusto Fernandes. Cambridge: Cambridge University Press, 1993. . Is the sanctity of life ethic terminally ill? KUHSE, Helga; SINGER, Peter (coord). Bioethics an antology. 2. ed. Oxford and Malden: Blackwell Publishing, 2006.

SOLER, Sebastián. Derecho penal argentino. 2. ed. Buenos Aires: TEA, 1963. t. III.

SOUZA, Maria Isabel de Azevedo. O princípio da exclusividade como nota distintiva do direito privado. In: MARTINS-COSTA, Judith (org.). A reconstrução do direito privado. São Paulo: Ed. RT, 2002.

SOUZA, Rabindranath V. A. Capelo de. O direito geral de personalidade. Coimbra: Coimbra Editora, 1995.

SPERONI, Diana Biágosch. ¿Procreación asistida o victimización? Buenos Aires: Lumen, 1993.

STEVENS, J. Dissenting Opinion. Supreme Court of the United States, 497 U.S. 261, Cruzan by Cruzan v. Director, Missouri Department of Health, Certiorari To The Supreme Court of Missouri, n. 88-1503 argued: Dec. 6, 1989, decided: june 25, 1990. Disponível em: http://www.law.cornell.edu/supct/html/historics/USSC_CR_0497_0261_ZD1.html. Acesso em: 08 jul. 2011.

STRETTON, Dean. The birth torts: damages for wrongful birth and wrongful life. Deakin LR, 10, p. 319-364, 2005.

SZANIAWSKI, Elimar. Direitos da personalidade e sua tutela. São Paulo: Ed. RT, 1993. RT, 2005.

Direitos da personalidade e sua tutela. 2. ed. rev. atual. e ampl. São Paulo: Ed. Direitos da personalidade na Antiga Roma. Revista de Direito Civil, Imobiliário, Agrário e Empresarial, p. 28-41, v. 3, São Paulo, jan.-fev. 1988. 2001.

O embrião excedente. Revista Trimestral de Direito Civil, ano 2, v. 8, out.-dez.

SZKLARZ, Eduardo. Quando começa a vida? Revista Super Interessante, jun. 2007. Disponível em: http://super.abril.com.br/revista/240a/materia_especial_261570.shtml?pagina=1. Acesso em: 29 abr. 2010.

SZTAJN, Rachel. Parecer CoBi 1999 - Assunto: eutanásia e meios extraordinários de prolongamento da vida. In: COHEN, Claudio; GARCIA, Maria (orgs.). Questões de 
bioética clínica: Pareceres da Comissão de Bioética do Hospital das Clínicas da Faculdade de Medicina da Universidade de São Paulo. Rio de Janeiro: Elsevier, 2007.

TAUPITZ, Jochen. The right to life of the unborn. Lex Medicinae - Revista Portuguesa de Direito da Saúde, Coimbra, Coimbra Editora, ano 3, n. 5, p. 5-14, jan.-jun. 2006.

TAYLOR, Charles. Sources of the self: the making of the modern identity. Cambridge: Harvard University Press, 1989.

TEIXEIRA, António Braz. Miguel Reale e o diálogo filosófico luso-brasileiro. In: LAFER, Celso; FERRAZ JR., Tércio Sampaio (orgs.). Direito, Política, Filosofia e Poesia. Estudos em Homenagem ao Professor Miguel Reale no seu Octagésimo Aniversário. São Paulo: Saraiva, 1992.

TELLES JR., Goffredo. Enciclopédia Saraiva do Direito. São Paulo: Saraiva, 1977. v. 28.

TEPEDINO, Gustavo. A tutela da personalidade no ordenamento civil-constitucional brasileiro. In: TEPEDINO, Gustavo (org.). Temas de Direito Civil. Rio de Janeiro: Renovar, 1999.

. Crise de fontes normativas e técnica legislativa na parte geral do Código Civil de 2002. In: TEPEDINO, Gustavo (coord.). A parte geral do novo Código Civil: estudos na perspectiva civil-constitucional. 2. ed. rev. e atual. Rio de Janeiro: Renovar, 2003.

TOBEÑAS, Castán José. Los derechos de la personalidad, RGLJ, t. VII-VIII, 1952. Los derechos de la personalidad, RGLJ, n. I-II, 1952.

TINANT, Eduardo Luis. Antología para una bioética jurídica. Buenos Aires: La Ley, 2004.

TOSCHI, Aldo. Por que unhas e cabelos continuam crescendo depois da morte? Disponível em: http://noticias.terra.com.br/educacao/vocesabia/noticias/0,,OI4608829EI8399,00-Por+que+unhas+e+cabelos+continuam+crescendo+depois+da+morte.html. Acesso em: 20 maio 2011.

TROTZIG, Marten A. The defective child and the actions for wrongful life and wrongful birth. Fam. L. Q., 14, p. 15-40, 1980-1981.

VARAUT, Jean-Marc. Lo possible y lo proibido. Trad. Rosa S. Corgatelli. Buenos Aires: Atlántida, 1991. 
VASCONCELOS, Pedro Pais de. Direito de personalidade. Coimbra: Almedina, 2006.

VENOSA, Sílvio de Salvo. Direito civil - Parte Geral. 2. ed. São Paulo: Atlas, 2002.

. Direito civil - Parte geral. 4. ed. São Paulo: Atlas, 2004. vol 1.

. Direito civil - Parte geral. 6. ed. São Paulo: Atlas, 2006. v. 1.

. Direito Civil - Direitos reais. 3. ed. atual. São Paulo: Atlas, 2003 (Coleção "Direito

civil", v. 5).

VIEIRA, Tereza Rodrigues. Bioética e direito. São Paulo: Jurídica Brasileira, 1999.

VILELA, Alexandra. Colheita de Órgãos e Tecidos em Doadores Vivos para Fins de Transplante - Artigos $19^{\circ}$ e $20^{\circ}$ da Convenção sobre Direitos do Homem e a Biomedicina. Lex Medicinae - Revista Portuguesa de Direito da Saúde, ano 1, n. 2, p. 27, Coimbra, Coimbra Editora, jul.-dez 2004.

VON MÜNCH, Ingo. La dignidad del hombre en el Derecho Constitucional. Trad. Jaime Nicolás Muñiz. Revista Espanhola de Direito Constitucional, n. 5, ano 2, p. 9-12, maioago. $1982 . \quad$ Disponível em: www.cepc.es/rap/Publicaciones/Revistas/6/REDC_005_009.pdf. Acesso em: 15 mar. 2011.

WALD, Arnoldo. Curso de direito civil brasileiro: introdução e parte geral. 8. ed. São Paulo: Ed. RT, 1995.

WEBER, Marx. Economía y sociedad. 2. ed. em espanhol. Trad. José Medina Echavarría et al. México: Fondo de Cultura Económica, 1964.

WEINRIB, J. Ernest. Duty to rescue. In: DWORKIN, Gerald (ed.). Morality, harm and the law. Boulder: Wetsview Press, 1994.

WIEACKER, Franz. História do Direito Privado Moderno. Privatrechtsgeschichte der Neuzeit unter Besonderer Berücksichtigung der deutschen Entwicklung. Trad. A. M. Botelho Espanha. 2. ed. Lisboa: Fundação Calouste Gulbenkian, 1993.

YOUNG, ED. Life and Death. PICU: ethical considerations. In: CIVETA, J. (ed.) Critical care. 2. ed. Philadelphia: J.B. Lippicott, 1993.

YOUNGNER, Stuart et al. Brain death and organ retrieval: a cross-sectional survey of knowledge and concepts among health professionals. Journal of the American Medical Association, n. 261, 1990. 
ZOBOLI, Elma Pavoni (rel.); GARCIA, Maria (rev.). Parecer CoBi 001/2006 - Assunto: Transplante de Coração utilizando como doador criança anencefálica. In: COHEN, Claudio; GARCIA, Maria (org.). Questões de bioética clínica: pareceres da Comissão de Bioética do Hospital das Clínicas da Faculdade de Medicina da Universidade de São Paulo. Rio de Janeiro: Elsevier, 2007.

\section{Outros documentos consultados:}

Assemblée plénière, 17 novembre 2000, Bull. ass. plén., n. 9. Disponível em: www.courdecassation.fr. Acesso em: 19 mar. 2009.

Assemblée plénière, 13 juillet 2001, 3 arrêts, Bull. n. 10; rapport de M. Blondet et conclusions de M. Sainte-Rose, BICC n. 542, p. 4. Disponível em: http://www.courdecassation.fr/publications_cour_26/rapport_annuel_36/rapport_2001_117 /troisieme_partie_jurisprudence_cour_124/assemblee_pleniere_125/assemblee_pleniere_5 986.html. Acesso em: 19/03/2009 às 20:30 hs.

Boletim do Ministério da Justiça, n. 340, p. 177-181, nov. 1984.

Bolsa aborto. Disponível em: http://www.conteudo.com.br/providafamilia/bolsa-aborto. Acesso em: 12 jul. 2011.

Casos: Parkinson v. St. James and Seacroft University Hospital NHS Trust (2001), EWCA Civ 530; [2001] 3 All $\quad$ ER 97 (In: http://www.bailii.org/ew/cases/EWCA/Civ/2001/530.html. Acesso dia 19.03.2009, às 21:54hs.); Rand v. East Dorset Health Authority (2000) EWCA Civ 560 (In: http://www.bailii.org/ew/cases/EWCA/Civ/2001/530.html. Acesso dia 19.03.2009, às 21:57hs.); Rees v. Darlington Memorial Hospital NHS Trust (2003) QB 20. Disponível em: http://www.publications.parliament.uk/pa/ld200203/ldjudgmt/jd031016/darl-2.htm. Acesso em: 19.03.2009.

Caso TACP, j. 12.11.1992. Disponível em: http://courses.dce.harvard.edu/ phils4/tacp.html. Acesso em: 15 abr. 2011. 
Comissão de SP reconhece feto como preso político. Instituto brasileiro de Direito de Família. Divulgado em 08 fev. 2007. Disponível em: http://www.ibdfam.org.br/?noticias\&noticia=1290. Acesso em: 25 nov. 2008.

Como votou Carlos Britto no caso de aborto de anencéfalo. Revista Consultor Jurídico, 28 abr. 2005. Disponível em: http://www.conjur.com.br/2005-abr28/votou_carlos_britto_aborto_anencefalo?pagina=3. Acesso em: 08 set. 2011.

Congenital Disabilities (Civil Liability) Act, de 22 jul. 1976. Disponível em: http://www.opsi.gov.uk/RevisedStatutes/Acts/ukpga/1976/cukpga_19760028_en_1. Acesso em: 19.03.2009.

Congressos y Jornadas Nacionales de Derecho Civil. Buenos Aires: La Ley, 2005.

Conselho Federal de Medicina. Res. CFM 1.826, 24 out. 2007. Diário Oficial da União, Brasília-DF, 06 dez. 2007. Seção I. Disponível em: http://www.portalmedico.org.br/resolucoes/cfm/2007/1826_2007.htm. Acesso em: 03 jun. 2011.

Consideraciones éticas y médicas acerca de un embarazo anencefálico. Comité de Ética del Hospital Privado de la Comunidad de Mar del Plata, 30 set. 1997. Disponível em: www.bioetica.org/dictamen7htm. Acesso em: 03 abr. 2009.

Constituição da OMS, de 07 de abril de 1948. Disponível em: http://apps.who.int/gb/bd/PDF/bd47/EN/constitution-en.pdf. Acesso em: 03 out. 2011.

Declaração de Mônaco: considerações sobre a bioética e os direitos da criança. Disponível em: http://www.ulbra.br/pesquisa/docs/declarmonaco.doc. Acesso em: 03 abr. 2009.

Declaração publicada no Recommendations on Ethical Issues in Obstetrics and Gynecology by the FIGO Committee for the Study of Ethical Aspects of Human Reproduction. Disponível em: http://www.figo.org/about_guidelines.asp. Acesso em: 27 abr. 2010.

ETHICS AND SOCIAL IMPACT COMMITTEE. Anencephalic infants as sources of transplantable organs by the Ethics and Social Impact Committee. Transplant Policy Center, Ann Arbor, New York: MI. Hastings Center Report, n. 5, p. 28-30, v. 18, 1988. 
Infants with Anencephaly as Organ Sources: Ethical Considerations. In: Committée on Bioethics, Pediatrics. n. 6, junho, parte 1, American Academy of Pediatrics, p. 1.116$1.119,1992$, v. 89.

Ley 1.044 - Anencefalia - B.O. 21 jul. 2003 CABA. Disponível em: http://www.intermunicipios.com/noticias/municipalnl/article_2003_07_25_1615.html.

Acesso em: 04 abr. 2009.

Morte encefálica. Disponível em: http://bvsms.saude.gov.br/html/pt/dicas/146morte_encefalica.html. Acesso em: 06 maio 2011.

Notícias do STF. Disponível em: http://www.stf.jus.br/portal/cms/verNoticiaDetalhe. asp?idConteudo=69682\&caixaBusca= N. Acesso em: 13 abr. 2010.

O Aborto e o Transplante de Tecido Fetal. Revista Bioética. v. 2, n. 1, Brasília, Conselho Federal de Medicina, 1994. Disponível em: www.portalmedico.org.br. Acesso em: 16 abr. 2009.

Observatorio Argentino de Bioética. Salud Pública y Anencefalia. Buenos Aires: FLACSO Argentina y CEDES, 2004. Disponível em: http://www.flacso.org.ar/uploaded_files/Publicaciones/dt1_Salud.Publica.y.Anencefalia.pd f. Acesso em: 05 ago. 2010.

Parecer-Consulta 24/2003 do CFM. Disponível em: http://www.portalmedico.org.br/pareceres/cfm/2003/24_2003.htm. Acesso em: 05 set. 2009.

Pro-Vidas denuncian aborto por anencefalia como 'regresión moral' y 'canibalismo'. Disponível em: http://www.aciprensa.com/noticia.php?n=5252. Acesso em: 12 abr. 2011.

Projeto de Lei 4.360, de 2004. Autor: Dep. Dr. Pinotti. Disponível em: http://www.ghente.org/doc_juridicos/p14360.htm. Acesso em: 04 abr. 2009.

Publicação do Conselho Regional de Medicina do Estado da Bahia, Salvador, 2004.

Responsabilidad Civil por la Privación de la Posibilidad de Abortar. Comentario a la STS, 1. a 18.12.2003, Working paper 217. Disponível em: www.indret.com. Acesso dia 19/03/2009. 
Salud Pública y Anencefalia. Buenos Aires, publicado por FLACSO Argentina e CEDES, 2004.

Disponível em:

http://www.flacso.org.ar/uploaded_files/Publicaciones/dt1_Salud.Publica.y.Anencefalia.pd f. Acesso em: 05 ago. 2010.

\section{Sites consultados:}

http://www.abctran.com.br/Conteudo/codigo_etica_medica.pdf. Acesso em: 07 abr. 2009.

http://www.anencephalie-info.org/p/index.php. Acesso em: 02 ago. 2011.

http://www.anencephalie-info.org/p/perguntas.php. Acesso em 15 abr. 2011.

http://www.bailii.org/ew/cases/EWCA/Civ/2001/530.html. Acesso em: 19 mar. 2009.

http://www.camara.gov.br/internet/agencia/imprimir.asp?pk=131466. Acesso em: 14 maio 2010.

http://www.camara.gov.br/proposicoesWeb/fichadetramitacao?idProposicao=424086.

Acesso em: 06 set. 2011.

http://caselaw.lp.findlaw.com/cgi-bin/getcase.pl?court=us\&vol=410\&invol=113. Acesso em: 23 ago. 2011.

http://www.courdecassation.fr/publications_cour_26/rapport_annuel_36/rapport_2001_117 /troisieme_partie_jurisprudence_cour_124/assemblee_pleniere_125/assemblee_pleniere_5 986.html. Acesso em: 19 mar. 2009.

http://www.cremesp.org.br/?siteAcao=Historia\&esc=3. Acesso em: 29 ago. 2011.

http://www.despenalizaciondelaborto.org.co/Sentencia-C-355-06-de-la-Corte. Acesso em: 19 abr. 2011.

http://www.esmpu.gov.br/dicionario/tikiindex.php?page=Organiza $\%$ C3\%A7\%C3\%A3o\%20Mundial $\% 20 \mathrm{da} \% 20 \mathrm{Sa} \% \mathrm{C} 3 \%$ BAde. Acesso em: 04 abr. 2009. 
http://www.ghente.org/doc_juridicos/resol1752.htm. Acesso em: 07 abr. 2009.

http://www.hojenoticias.com.br/direito/aborto-em-casos-de-anencefalia-esta-ligado-apratica-da-eutanasia-diz-deputado/. Acesso em: 21 set. 2009.

http://www.in.gov/judiciary/opinions/archive/04150301.bed.html. Acesso em: 26 mar. 2009.

www.kluwer.nl. Acesso em: 23 ago. 2008.

http://michaelis.uol.com.br/moderno/portugues/index.php?lingua=portuguesportugues\&palavra=viável. Acesso em: 09 set. 2011.

http://www.ohchr.org/Documents/Publications/training9add1.pdf. Acesso em: 19 abr. 2011.

http://peisker.net/ffa/Capacity\%20(Tort).htm. Acesso em: 19 mar. 2009.

http://www.pensador.info/p/aborto/1/. Acesso em: 04 abr. 2009.

http://www.pensador.info/p/jean_paul_sartre_frases/2/. Acesso em: 04 abr. 2009.

http://www.pensador.info/p/morte/1/. Acesso em: 04 abr. 2009.

http://www.pensador.info/p/vida_e/1/. Acesso em: 04 abr. 2009.

http://www.pericias-forenses.com.br/cronota.htm. Acesso em: 18 fev. 2010.

http://www.publications.parliament.uk/pa/ld200203/ldjudgmt/jd031016/darl-2.htm. Acesso em: 19 mar. 2009.

http://www.redetel.gov.ar/Normativa/Archivos\%20de\%20Normas/CodigoCivil.htm. Acesso em: 11 fev. 2010. 
http://www.searo.who.int/LinkFiles/About_SEARO_const.pdf. Acesso em: 14 out. 2009.

http://www.sltrib.com/2003/Jan/01012003/utah/16415.asp. Acesso dia 19.03.2009.

http://www.stf.jus.br/arquivo/cms/noticiaNoticiaStf/anexo/adi3510relator.pdf. Acesso em: 06 abr. 2010.

http://www.stf.jus.br/portal/cms/verNoticiaDetalhe. asp?idConteudo $=69672 \&$ caixaBusca $=$ N. Acesso em: 13 abr. 2010.

http://www.stf.jus.br/portal/cms/verNoticiaDetalhe.asp?idConteudo=69693\&caixaBusca= N. Acesso em: 13 abr. 2010.

http://www.tjrs.jus.br/. Acesso em: 24 out. 2008. 